\title{
Weak Convergence Theorem of Khan Iterative Scheme for Nonself I-Nonexpansive Mapping
}

\author{
Poonam Lata Sagar ${ }^{1}$, S. K. Malhotra ${ }^{2}$ \\ ${ }^{I}$ Asst. Prof. Dept. of Applied Mathematics \& Comp. Science, SATI (Deg), Vidisha (M.P.) India \\ ${ }^{2}$ Head of dept. of Mathematics, Govt. S. G. S. P.G. College Ganj Basoda, Distt Vidisha (M.P.) India
}

\begin{abstract}
In this paper, we prove the weak convergence of a modified Khan iteration for nonself I nonexpansive mapping in a Banach space which satisfies Opial's condition. Our result extends and improves these announced by S. Chornphrom and S.Phonin [Weak Converges Theorem of Noor iterative Scheme for Nonself I-Nonexpansive mapping, Thai Journal of Mathematics Volume 7(2009) no.2:311-317].

Keywords: Khan iterative scheme; weak convergence; nonself nonexpansive mapping; fixed point; Banach space.

2000 Mathematics Subject Classification: 47H09; $47 H 10$ (2000 MSC)
\end{abstract}

\section{Introduction}

Let $\mathrm{E}:=(\mathrm{E},\|\|$.$) be a real Banach space, \mathrm{K}$ be a nonempty convex subset of $\mathrm{E}$, and $\mathrm{T}$ be a self mapping of $\mathrm{K}$. The Mann iteration [9] is defined as $\mathrm{x} 1 \in \mathrm{K}$ and

$$
\begin{aligned}
& \mathrm{xn}+1=\left(1-\alpha_{n}\right) x_{n}+\alpha_{n} T x_{n}, \quad n \geq 1 . \quad \text { (1.1) The Ishikawa iteration [5] is defined as } x 1 \in K \text { and } \\
& \mathrm{y}_{\mathrm{n}}=\left(1-\beta_{\mathrm{n}}\right) \mathrm{x}_{\mathbf{n}}+\beta_{\mathrm{n}} \mathrm{T} \mathrm{x}_{\mathbf{n}} \\
& \mathrm{xn}_{\mathrm{n}}+1=\left(1-\alpha_{\mathrm{n}}\right) \mathrm{x}_{\mathrm{n}}+\alpha_{\mathrm{n}} \mathrm{T} \mathrm{y}_{\mathrm{n}}, \mathrm{n} \geq 1 \text {. }
\end{aligned}
$$

The Noor iteration $[8]$ is defined as $\mathrm{x} 1 \in \mathrm{K}$ and $\mathrm{z}_{\mathbf{n}}=\left(1-\gamma_{\mathbf{n}}\right) \mathrm{x}_{\mathbf{n}}+\gamma_{\mathbf{n}} T \mathrm{x}_{\mathbf{n}}$

$$
y_{n}=\left(1-\beta_{n}\right) x_{n}+\beta_{n} T z_{n}
$$

$$
x_{n}+1=\left(1-\alpha_{n}\right) x_{n}+\alpha_{n} T y_{n}, \quad n \geq 1,
$$

The Khan iteration [9] is defined as $\mathrm{x} 1 \in \mathrm{K}$ and

$$
\begin{aligned}
X_{n+1} & =\left(1-\alpha_{n}\right) T^{n} x_{n}+\alpha_{n} S^{n} y_{n} \\
y_{n} & =\left(1-\beta_{n}\right) x_{n}+\beta_{n} T^{n} x_{n}, \quad n \geq 1,
\end{aligned}
$$

Where $\left\{\alpha_{n}\right\},\left\{\beta_{n}\right\},\left\{\gamma_{n}\right\} \subset(0,1]$.

In the above taking $\beta \mathrm{n}=0$ in (1.2) and taking $\beta \mathrm{n}=0, \gamma_{\mathrm{n}}=0$ in (1.3) we Obtain iteration (1.1).

In 1975, Baillon [1] first introduced nonlinear ergodic theorem for general non-expansive mapping in a Hilbert space $\mathrm{H}$ : if $\mathrm{K}$ is a closed and convex subset of $\mathrm{H}$ and $\mathrm{T}$ has a fixed point, then for every $x \in K,\left\{T^{n} x\right\}$ is a weakly almost convergent, as $n \rightarrow \infty$, to a fixed point of T.It was also shown by Pazy[11] that if $\mathrm{H}$ is a real Hilbert space and (1/n) $\sum_{i=0}^{n-1} \mathrm{~T}^{\mathbf{i}} \mathrm{x}$ converges weakly, as $\mathrm{n} \rightarrow \infty$, to $\mathrm{y} \in \mathrm{K}$, $y \in F(T)$.

In 1941, Tricomi introduced the concept of a quasi-nonexpansive mapping for real functions. Later Diaz and Metcalf [2] and Dotson [3] studied quasi- nonexpansive mappings in Banach spaces. Recently, this concept was given by Kirk [6] in metric spaces which we adapt to a normed space as the following: $\mathrm{T}$ is called a quasinonexpansive mapping provided for all $\mathrm{x} \in \mathrm{K}$ and $\mathbf{f} \in \mathrm{F}(\mathrm{T})$.

$$
\|\mathrm{T} x-\mathbf{f}\| \leq\|\mathbf{x}-\mathbf{f}\|
$$

Recall that a Banach space $E$ is said to satisfy Opial's condition [10] if, for each sequence $\left\{x_{n}\right\}$ in $\mathrm{E}$, the condition $\mathrm{x}_{\mathrm{n}} \rightarrow \mathrm{x}$ implies that 
$\lim _{n \rightarrow \infty} \sup \left\|\mathrm{x}_{\mathrm{n}}-\mathrm{x}\right\|<\lim _{n \rightarrow \infty} \sup \left\|\mathrm{x}_{\mathrm{n}}-\mathrm{y}\right\|$

for all $\mathrm{y} \in \mathrm{E}$ with $\mathrm{y} \neq \mathrm{x}$. It is well known from [10] that all $\mathrm{lp}$ spaces for $1<\mathrm{p}<\infty$ have this property. However, the $1 \mathrm{p}$ spaces do not, unless $\mathrm{p}=2$. The following definitions and statements are needed for the proof of our thorem.

Let $\mathrm{K}$ be a closed convex bounded subset of uniformly convex Banach spaces $\mathrm{E}$ and $\mathrm{T}$ self-mapping of $\mathrm{E}$. Then $\mathrm{T}$ is called nonexpansive on $\mathrm{K}$ if

$$
\|\mathrm{Tx}-\mathrm{Ty}\| \leq\|\mathrm{x}-\mathrm{y}\|
$$

for all $x, y \in K$. Let $F(T):=\{x \in K: T x=x\}$ be denote the set of fixed points of a mapping $T$.

Let $\mathrm{K}$ be a subset of a normed space $\mathrm{E}$ and $\mathrm{T}$ and $\mathbf{I}$ self-mappings of $\mathbf{K}$. ThenT is called $\mathbf{I}$-nonexpansive on $\mathrm{K}$ if for all $\mathrm{x}, \mathrm{y} \in \mathrm{K}[14]$.

$$
\|\mathrm{Tx}-\mathrm{Ty}\| \leq\|\mathrm{Ix}-\mathbf{I x}\|
$$

A mapping $\mathrm{T}$ is called $\mathbf{I}$-quasi-nonexpansive on

$$
\|\mathrm{Tx}-\mathrm{f}\| \leq\|\mathrm{Ix}-\mathrm{f}\|
$$

for all $x, y \in K$ and $\mathbf{f} \in \mathrm{F}(\mathrm{T}) \cap \mathrm{F}(\mathbf{I})$.

A subset $\mathrm{K}$ of $\mathrm{E}$ is said to be a retract of $\mathrm{E}$ if there exists a continuous map $\mathrm{P}: \mathrm{E} \rightarrow \mathrm{K}$ such that $\mathrm{P}$ $\mathrm{x}=\mathrm{x}$ for all $\mathrm{x} \in \mathrm{K}$. A map $\mathrm{P}: \mathrm{E} \rightarrow \mathrm{E}$ is said to be a retraction if $\mathrm{P}^{2}=\mathrm{P}$. It follows that if a map $\mathrm{P}$ is a retraction, then $\mathrm{Py}=\mathrm{y}$ for all $\mathrm{y}$ in the range of $\mathrm{P}$. A set $\mathrm{K}$ is optimal if each point outside $\mathrm{K}$ can be moved to be closer to all points of $\mathbf{K}$. Note that every nonexpansive retract is optimal. In strictly convex Banach spaces, optimal sets are closed and convex. However, every closed convex subset of a Hilbert space is optimal and also a nonexpansive retract.

Remark 1.1. From the above definitions it is easy to see that if $F(T)$ is nonempty, a nonexpansive mapping must be quasi-nonexpansive, and linear quasi- nonexpansive mappings are nonexpansive. But it is easily seen that there exist nonlinear continuous quasi-nonexpansive mappings which are not nonexpansive. There are many results on fixed points on nonexpansive and quasi-nonexpansive mappings in Banach spaces and metric spaces. For example, Petryshyn and Williamson [12] studied the strong and weak convergence of the sequence of certain iterates to a fixed point of quasi-nonexpansive mapping. Their analysis was related to the convergence of Mann iterates studied by Dotson [3]. Subsequently, Ghosh and Debnath [4] considered the convergence of Ishikawa iterates of quasi- nonexpansive mappings in Banach spaces. Later Temir and Gul [15] proved the weakly convergence theorem for I -asymptotically quasi-nonexpansive mapping defined in Hilbert space. In [16], the convergence theorems of iterative schemes for nonexpansive mappings have been presented and generalized.

In [13], Rhoades and Temir considered $\mathrm{T}$ and $\mathbf{I}$ self-mappings of $\mathbf{K}$, where $\mathrm{T}$ is $\mathbf{I}$-nonexpansive mapping. They established the weak convergence of the sequence of Mann iterates to a common fixed point of T and I. More precisely, they proved the following theorems.

Theorem (Rhoades and Temir [13]): Let $\mathrm{K}$ be a closed convex bounded subset of uniformly convex Banach space $\mathrm{E}$, which satisfies Opial's condition, and let $\mathrm{T}$, I self-mappings of $\mathrm{K}$ with $\mathrm{T}$ be an $\mathbf{I}$ nonexpansive mapping, $\mathbf{I}$ a nonex- pansive on $\mathbf{K}$. Then, for $\mathrm{x} 0 \in \mathbf{K}$, the sequence $\{\mathbf{x} \mathbf{n}\}$ of modified Noor iterates converges weakly to common fixed point of $F(T) \cap F(I)$.

In the above theorem, $\mathrm{T}$ remains self-mapping of a nonempty closed convex subset $\mathrm{K}$ of a uniformly convex Banach space. If, however, the domain $\mathrm{K}$ of $\mathrm{T}$ is a proper subset of $\mathrm{E}$ and $\mathrm{T}$ maps $\mathrm{K}$ into $\mathrm{E}$ then, the iteration formula (1.1) may fail to be well defined. One method that has been used to overcome this in the case of single operator $\mathrm{T}$ is to introduce a retraction $\mathrm{P}: \mathrm{E} \rightarrow \mathrm{K}$ in the recursion formula (1.1) as follows: $\mathrm{x}_{1} \in \mathrm{K}$,

$$
x_{n}+1=\left(1-\alpha_{n}\right) x_{n}+\alpha_{n} P T x_{n}, n \geq 1 \text {. }
$$

In [7], Kiziltunc and Ozdemir considered $\mathrm{T}$ and $\mathbf{I}$ are nonself mapping of $\mathrm{K}$ where $\mathrm{T}$ is an $\mathbf{I}$ nonexpensive mapping. They established the weak convergence of the sequence of the modified Ishikawa iterative scheme to a common fixed point of $\mathrm{T}$ and $\mathbf{I}$.

$$
y_{n}=P\left(\left(1-\beta_{n}\right) x_{n}+\beta_{n} T x_{n}\right)
$$


$\mathrm{x}_{\mathrm{n}+1}=\mathrm{P}\left(\left(1-\alpha_{\mathrm{n}}\right) \mathrm{x}_{\mathrm{n}}+\alpha_{\mathrm{n}} \mathrm{T} \mathrm{y}_{\mathrm{n}}\right), \quad \mathrm{n} \geq 1$.

In this paper, we consider $\mathrm{T}$ and $\mathbf{I}$ are nonself mappings of $\mathbf{K}$, where $\mathrm{T}$ is an $\mathbf{I}$-nonexpansive mappings. We prove the weak convergence of the sequence of modified Noor iterative scheme to a common fixed point of $F(T) \cap F(I)$.

\section{Main Results}

In this section, we prove the weak convergence theorem.

Theorem 2.1. Let $\mathrm{K}$ be a closed convex bounded subset of a uniformly convex Banach space $\mathrm{E}$ which satisfies Opial's condition, and let T, $\mathbf{I}$ nonself mappings of $\mathbf{K}$ with $\mathrm{T}$ be an $\mathbf{I}$-nonexpansive mapping, $\mathbf{I}$ a nonexpansive on $\mathrm{K}$. Then, for $\mathrm{x} 0 \in \mathrm{K}$, the sequence $\left\{\mathrm{x}_{\mathbf{n}}\right\}$ of modified Khan iterates defined by $\mathrm{x}_{1} \in \mathrm{K}$,

$$
\begin{aligned}
& Z_{n}=\left(1-\gamma_{n}\right) x_{n}+\gamma_{n} T^{n} x_{n}, \\
& y_{n}=\left(1-\beta_{n}\right) x_{n}+\beta_{n} S_{n} Z_{n,} \\
& x_{n+1}=\left(1-\alpha_{n}\right) x_{n}+\alpha_{n} P^{n} y_{n},
\end{aligned}
$$

$$
\mathrm{n} \geq 1
$$

converges weakly to common fixed point of $\mathrm{F}(\mathrm{T}) \cap \mathrm{F}(\mathbf{I})$.

Proof. If $F(T) \cap F(I)$ is nonempty and a singleton, then the proof is complete. We will assume that $F(T) \cap F(I)$ is nonempty and that $\mathrm{F}(\mathrm{T}) \cap \mathrm{F}(\mathbf{I})$ is not a singleton.

$$
\begin{aligned}
& \left\|x_{n+1}-f\right\|=\left\|\left(1-\alpha_{n}\right) x_{n}+\alpha_{n} P^{n} y_{n}-f\right\| \\
= & \left\|\left(1-\alpha_{n}\right) x_{n}+\alpha_{n} P^{n} y_{n}-\left(1-\alpha_{n}+\alpha_{n}\right) f\right\| \\
\leq & \left(1-\alpha_{n}\right)\left\|x_{n}-f\right\|+\alpha_{n}\left\|P^{n} y_{n}-f\right\| \\
\leq & \left(1-\alpha_{n}\right)\left\|x_{n}-f\right\|+\alpha_{n} K_{n}\left\|y_{n}-f\right\|
\end{aligned}
$$

and

$$
\begin{aligned}
& \left\|y_{n}-f\right\|=\left\|\left(1-\beta_{n}\right) x_{n}+\beta_{n} S^{n} z_{n}-f\right\| \\
= & \left\|\left(1-\beta_{n}\right) x_{n}+\beta_{n}\left(S^{n} z_{n}-f\right)\right\| \\
\leq & \left(1-\beta_{n}\right)\left\|x_{n}-f\right\|+\beta_{n}\left\|S^{n} z_{n}-f\right\| \\
\leq & \left(1-\beta_{n}\right)\left\|x_{n}-f\right\|+\beta_{n} K_{n}\left\|z_{n}-f\right\|
\end{aligned}
$$

and also, we get

$$
\begin{aligned}
& \left\|z_{n}-f\right\|=\left\|\left(1-\gamma_{n}\right) x_{n}+\gamma_{n} T^{n} x_{n}-f\right\| \\
& =\|\left(1-\gamma_{n}\right) x_{n}+\gamma_{n}\left(T^{n} x_{n}-f \|\right. \\
& \leq\left(1-\gamma_{n}\right)\left\|x_{n}-f\right\|+\gamma_{n}\left\|T^{n} x_{n}-f\right\| \\
& \leq\left(1-\gamma_{n}\right)\left\|x_{n}-f\right\|+\gamma_{n} K_{n}\left\|x_{n}-f\right\|
\end{aligned}
$$

Substituting (2.4) in (2.3), we have

$$
\left\|y_{n}-f\right\| \leq\left(1-\beta_{n}\right)\left\|x_{n}-f\right\|+K_{n} \beta_{n}\left(1-\gamma_{n}+K_{n} \gamma_{n}\right)\left\|x_{n}-f\right\|
$$

Substituting (2.5) in (2.2), we have

$$
\begin{aligned}
& \left\|x_{n+1}-f\right\| \leq\left(1-\alpha_{n}\right)\left\|x_{n}-f\right\|+\alpha_{n} K_{n}\left(1-\beta_{n}+K_{n} \beta_{n}-K_{n} \beta_{n} \gamma_{n}+K_{n}^{2} \beta_{n} \gamma_{n}\right)\left\|x_{n}-f\right\| \\
& \leq\left(1-\alpha_{n}+K_{n} \alpha_{n}-K_{n} \alpha_{n} \beta_{n}+K_{n}^{2} \alpha_{n} \beta_{n}-K_{n}^{2} \alpha_{n} \beta_{n} \gamma_{n}+K_{n}^{3} \alpha_{n} \beta_{n} \gamma_{n}\right)\left\|x_{n}-f\right\| \\
& \leq\left[1-\alpha_{n}\left(K_{n}-1\right)+\alpha_{n} \beta_{n} K_{n}\left(K_{n}-1\right)+\alpha_{n} \beta_{n} \gamma_{n} K_{n}^{2}\left(K_{n}-1\right)\right]\left\|x_{n}-f\right\|
\end{aligned}
$$


Thus $\alpha_{\mathrm{n}} \neq 0, \beta_{\mathrm{n}} \neq 0$ and $\gamma \neq 0$. Since $\left\{K_{n}\right\}$ is a nonincreasing bounded sequence and hence $\mathrm{K}_{\mathrm{n}}<1$ implies that $\sum_{n=1}^{\infty}\left(K_{n}-1\right)<\infty$. Then $\lim _{n \rightarrow \infty}\left\|x_{n}-f\right\|$ exists.

Now we show that $\left\{x_{n}\right\}$ converges weakly to a common fixed point of $T$ and $\mathbf{I}$. The sequence $\left\{x_{n}\right\}$ contains a subsequence which converges weakly to a point in $\mathrm{K}$. Let $\left\{\mathrm{x}_{\mathrm{nk}}\right\}$ and $\left\{\mathrm{x}_{\mathrm{mk}}\right\}$ be two subsequences of $\left\{\mathrm{x}_{\mathbf{n}}\right\}$ which converge weak to $\mathbf{f}$ and $q$, respectively. We will show that $\mathbf{f}=q$. Suppose that $\mathrm{E}$ satisfies Opial's condition and that $f \neq \mathrm{q}$ is in weak limit set of the sequence $\left\{\mathrm{x}_{\mathrm{n}}\right\}$. Then $\left\{\mathrm{x}_{\mathrm{nk}}\right\} \rightarrow \mathrm{f}$ and $\left\{\mathrm{x}_{\mathrm{mk}}\right\} \rightarrow \mathrm{q}$, respectively. Since $\lim _{n \rightarrow \infty}\left\|x_{n}-f\right\|$ exists for any $\mathrm{f} \in \mathrm{F}(\mathrm{T}) \cap \mathrm{F}(\mathbf{I})$, by opial's condition, we conclude that

$$
\begin{aligned}
\lim _{n \rightarrow \infty}\left\|\mathrm{x}_{\mathrm{n}}-\mathrm{f}\right\|= & \lim _{k \rightarrow \infty}\left\|\mathrm{x}_{\mathrm{nk}}-\mathrm{f}\right\|<\lim _{k \rightarrow \infty}\left\|\mathrm{x}_{\mathrm{nk}}-\mathrm{q}\right\| \\
= & \lim _{n \rightarrow \infty}\left\|\mathrm{x}_{\mathrm{n}}-\mathrm{q}\right\|=\lim _{j \rightarrow \infty}\left\|\mathrm{x}_{\mathrm{mj}}-\mathrm{q}\right\| \\
& <\lim _{j \rightarrow \infty}\left\|\mathrm{x}_{\mathrm{mj}}-\mathrm{f}\right\|=\lim _{n \rightarrow \infty}\left\|\mathrm{x}_{\mathrm{n}}-\mathrm{f}\right\|
\end{aligned}
$$

This is a contradiction. Thus $\left\{x_{n}\right\}$ converges weakly to an element of $F(T) \cap F(I)$. This completes the proof.

Corollary 2.2.(Kumam et al.[8, Theorem 2.1]) Let $\mathrm{K}$ be a closed convexbounded subset of a uniformly convex Banach space X, which satisfies Opial's condition, and let T, I self-mappings of $\mathrm{K}$ with $\mathrm{T}$ be an $\mathbf{I}$ -quasi-nonexpansive mapping, $\mathbf{I}$ a nonexpansive on $\mathrm{K}$. Then, for $\mathrm{x}_{0} \in \mathrm{K}$, the sequence $\left\{\mathrm{x}_{\mathrm{n}}\right\}$ of three-step Noor iterative scheme defined by (1.3) converges weakly to common fixed point of $F(T) \cap F(\mathbf{I})$.

Corollary2.3. (Kiziltunc and Ozdemir [7, Theorem 2.1]) Let $\mathrm{K}$ be a closed con- vex bounded subset of a uniformly convex Banach space E, which satisfies Opial's condition, and let T, I nonself mappings of $\mathrm{K}$ with $\mathrm{T}$ be an $\mathbf{I}$-nonexpansive map- ping, $\mathbf{I}$ a nonexpansive on $\mathrm{K}$. Then, for $\mathrm{x}_{1} \in \mathrm{K}$, the sequence $\left\{\mathrm{x}_{\mathrm{n}}\right\}$ of modified Ishikawa iterates defined by (1.9) converges weakly to common fixed point of $F(T) \cap F(I)$.

Theorem 2.4. Let $\mathrm{K}$ be a closed convex bounded subset of a uniformly convex Banach space E, which satisfies Opial's condition, and let T, I nonself mappings of $\mathbf{K}$ with $\mathrm{T}$ be an $\mathbf{I}$-nonexpansive mapping, I a nonexpansive on $\mathrm{K}$. Then, for $\mathrm{x} 1 \in \mathrm{K}$, the sequence $\left\{\mathrm{x}_{\mathrm{n}}\right\}$ of Mann converges weakly to common fixed point of $\mathrm{F}(\mathrm{T}) \cap \mathrm{F}(\mathbf{I})$.

Proof. Putting $\gamma_{\mathrm{n}}=0$ and $\beta_{\mathrm{n}}=0$ in Theorem 2.1, we obtain the desired result.

\section{References}

[1] J. B. Baillon, Un theorem de type ergodique pour les contractions non lineaires dans un espace de Hilbert, Comptes Rendus de l'Academie des Sciences de Paris, Serie A 280(1975), no. 22, 1511-1514.

[2] J. B. Diaz and F. T. Metcalf, On the set of sub sequential limit points of successive approximations, Transaction of the American Mathematical Society 135(1969), 459-485.

[3] W. G. Dotson Jr., On the Mann iterative process, Transactions of the American Mathematical Society 149(1970), no. 1, 65-73.

[4] M.K.Ghosh and L.Debnath, Convergence of Ishikawa iterates of quasi -nonexpansive mappings, Journal of Mathematical Analysis and Applications 207(1997), no. 1, 96-103.

[5] S. Ishikawa, Fixed points by a new iteration method, Proc. Am. Math. Soc.44(1974) 147-150.

[6] W. A. Kirk, Remarks on approximation and approximate fixed points in metric fixed point theory, Annales Universitatis Mariae Curie-Sklodowska. Sectio A 51(1997), no. 2, 167-178.

[7] H. Kiziltunc and M. Ozdemir, On convergence theorem for nonself I- nonexpansive mapping in Banach spaces, Applied Mathematical Sciences 1(2007), no. 48, 2379-2383.

[8] P. Kumam, W. Kumethong and N. Jewwaiworn, Weak convergence Theo- rems of three-step Noor iterative scheme for I-quasinonexpansive mappings in Banach spaces, Applied Mathematical Sciences 2(2008), no. 59, 2915-2920.

[9] S.H.Khan, Y.J., M. Abbas, Convergence to commaon fixed points by a modifyed Iteration process, Journal of Appl. Math. andcomput. doi. 10. 1007/s 12190-010-0381-z.

[10] Z. Opial, Weak convergence of the sequence of successive approximations for nonexpansive mappings, Bulletin of the American Mathematical Society 73(1967), 591-597.

[11] A.Pazy, On the asymptotic behavior of iterates of nonexpansive mappings in Hilbert space, Israel Journal of Mathematics 26(1977), no. 2 , 197-204.

[12] W. V. Petryshyn and T. E. Williamson Jr., Strong and weak convergence of the sequence of successive approximations for quasinonexpansive mappings, Journal of Mathematical Analysis and Application 43(1973), 459-497.

[13] B. E. Rhoades and S. Temir, Convergence theorems for I-nonexpansive mapping, to appear in International Journal of Mathematics and Mathematical Sciences.

[14] N. Shahzad, Generalized I-nonexpansive maps and best approximations in Banach spaces, Demon-stratio Mathematical 37(2004), no. 3, 597-600.

[15] S. Temir and O. Gul, Convergence theorem for I-asymptotically quasi- nonexpansive mapping in Hilbert space, Journal of Mathematical Analysis and Applications 329(2007) 759-765.

[16] H. Zhou, R. P. Agarwal, Y. J. Cho, and Y. S. Kim, Nonexpansive mappings and iterative method in uniformly convex Banach spaces, Georgian Mathematical Journal 9(2002), no. 3, 591-600. 